\title{
Use of Tubularized Incised Plate Urethroplasty for Secondary Hypospadias Repair or Repair in Circumcised Patients
}

\author{
Seyed A. Mousavi
}

Department of Pediatric Surgery, Faculty of Medicine, Mazandaran University of Medical Sciences, Sari, Iran

\begin{abstract}
Purpose: To retrospectively review our experience of the tubularized incised plate (TIP) urethroplasty in a series of reoperative hypospadias repairs or circumcised children.

Materials and Methods: Between September 2001 and September 2007, 17 children (mean 4.6 years, range 7 months to 15 years), were referred for hypospadias re-operation. Some of these patients had previously undergone circumcision and missed hypospadias. In all cases, the TIP urethroplasty was covered with an additional layer of subcutaneous tissue or dartos flap. The original location, associated complications and results were recorded.

Results: There were 4 (30.7\%), incidences of complications of TIP re-operation, 2 meatal stenosis, one stenosis with small fistula and one dehiscence. Re-operation was necessary in only one patient of our series (7.6\%) and the others were cured by dilatation. No complications occurred in the circumcised patents.

Conclusion: Using TIP urethroplasty as described by Snodgrass, is a suitable method for treating primary and re-operative cases. It can also be used successfully in patients, who do not have a healthy skin flap and in circumcised patients when there is a lack of foreskin.
\end{abstract}

Key words: urethroplasty; hypospadias; urethral plate; circumcision

Int Braz J Urol. 2008; 34: 609-16

\section{INTRODUCTION}

Numerous methods for repair of hypospadias have been introduced. However, urethrocutaneous fistula or neourethral dehiscence was the most troublesome complication. These problems are the main difficulty in re-operations, because in these cases urethral reconstruction is required, but only a small amount of penile foreskin is available. On the other hand, the vasculature of previously operated tissues may be suboptimal, resulting in further complications. In 1994, Warren Snodgrass described a procedure using tubularized incised plate (TIP) urethroplasty with excellent results (1). The TIP urethroplasty has also been used successfully in re-operative and complex hypospadias repairs (2-4).

Although, tubularized incised plate urethroplasty is well described, there are few reported experiences pertaining to complicated hypospadias or circumcised patients that are re-operated by this technique. We report our results in using the TIP urethroplasty with a local flap in previous hypospadias failures and circumcised patients with intact urethral plate.

\section{MATERIALS AND METHODS}

Between September 2001 and September 2007, 134 children (mean age 4 years, range 7 months 
to 15 years) were referred for hypospadias repair or re-operation. Four patients had fistula after circumcision due to the aggressive use of cautery and thus were excluded from this study. Seventeen [17] patients had a failed hypospadias repair or circumcised without reconstruction, while 113 had primary hypospadias.

This study included 17 patients (aged 18 months to 15 years, mean 4.6 years) who had previously undergone 1-to 3 failed hypospadias repair or circumcision. The previous techniques utilized Mathieu repair in two, Thiersh-Duplay in four, failed on lay flap in one and unknown in six (Table-1).Also, four [4] children were circumcised without hypospadias repair. Glanular hypospadias also were excluded from this study. The interval from the last surgery to TIP re-operation was 6 months to 11 years. Testosterone was administered in 3 patients prior to re-operation.

After the primary evaluation, tubularized incised plate urethroplasty was performed for correction of complications related to the previous hypospadias surgery. All of the re-operations were performed by the same surgeon.
After general anesthesia, a stay suture was placed through the glans for traction. Then the penis was degloved and any meatal stenosis or fistula opened widely, to prevent subsequent stricture formation. An artificial erection was carried out for ventral curvature, as a necessary step. Dorsal placation was performed on 3 patients. Parallel incisions separated the glans wings from the urethral plate and the plate was incised in the mid-line as described by Snodgrass (1). A 6F or 8F stent was passed into the bladder for post operative urinary diversion, then, urethroplasty was performed using subcuticular $6 / 0$ vicryl interrupted sutures. The epithelium of the urethral plate was inverted toward the lumen to avoid fistula formation. Care was taken to avoid suturing the distal urethral plate too snugly, which may result in meatal stenosis. Usually only 1 or 2 sutures beyond the mid glans level of the plate were needed, leaving the neomeatus oval in configuration (3). In long neourethra, we used a ventral dartos pedicle to cover the repair, while the second layer was placed by adjacent dartos and peri-urethral tissues and in

Table 1 - Summary of patients' characteristics and results.

\begin{tabular}{cccc}
\hline Age (years) & N of Previous Operations & Location & Complication \\
\hline 3 & 1 (T. Duplay) & $\mathrm{D}$ & Stenosis \\
15 & 3 (unknown) & $\mathrm{D}$ & None \\
9 & 3 (unknown) & $\mathrm{SC}$ & None \\
3 & 1 (Mathieu) & $\mathrm{SC}$ & None \\
2 & 2 (T. Duplay) & $\mathrm{D}$ & Stenosis/fistula \\
4 & 1 (onlay flap) & $\mathrm{P}$ & Glanuloplasty dehisced \\
4 & 1 (unknown) & $\mathrm{SC}$ & Stenosis \\
5 & 1 (unknown) & $\mathrm{D}$ & None \\
2 & 1 (T. Duplay) & $\mathrm{SC}$ & None \\
4 & 1 (unknown) & $\mathrm{D}$ & None \\
3 & 1 (T. Duplay) & $\mathrm{SC}$ & None \\
2 & 1 (unknown) & $\mathrm{M}$ & None \\
3 & 1 (Mathieu) & $\mathrm{SC}$ & None \\
5 & 1 (circumcision) & $\mathrm{SC}$ & None \\
10 & 1 (circumcision) & $\mathrm{SC}$ & None \\
3 & 1 (circumcision) & $\mathrm{M}$ & None \\
1.5 & 1 (circumcision) & $\mathrm{SC}$ & None \\
\hline
\end{tabular}

SC $=$ sub coronal $; D=$ distal shaft $; M=$ mid shaft $P=$ proximal. 
some patients with a satisfactory prepuce we used dorsal tissue.

In circumcised patients, the neourethra was covered with a mini pedicle of subcutaneous tissues dissected from the small remained dorsal skin. Because the urethral plate was intact in these patients, the urethroplasty was easier to perform.

The catheter within the urethra was secured distally to the glans with the traction suture. A compression dressing was applied. All patients were discharged from the hospital one day after surgery. Catheter and dressing were removed after four days. Patients were examined twice in the first month, with follow-up within a 6 month period. Patients who had an acceptable cosmetic appearance and voided from the end of the penis with no difficulty were considered as successful surgery.

\section{RESULTS}

The demographic characteristics of patients are presented in Table-1. The mean follow-up after surgery was 15 months (range 4-24 months). There were four complications; a four-year old boy that was referred after a failed repair by on-lay flap technique. It was our first experience and we placed a small Foley catheter at surgery instead of a stent. The day after surgery he developed severe bladder spasms. Subsequently, the patient's glanuloplasty dehisced which required re-operation. Two children developed meatal stenosis that responded to 2-3 times calibration. The fourth child developed a pin hole fistula and stenosis. After 6 weeks calibration (twice per week), both of them were cured. The remaining 13 patients including circumcised patients had excellent results, i.e. a strong and vertical urinary stream was observed and the slit-like meatus was constructed at the tip of the glans (Table-1). We had no complications in the four circumcised patients with hypospadias.

\section{COMMENTS}

In the correction of complicated hypospadias, it is preferable to use vascularized preputial or penile skin. When genital skin is unavailable or insufficient, it may be necessary to choose extragenital tissues such as skin, bladder mucosa and buccal mucosa, in order to complete a successful repair. Duckett et al.(5) comment that buccal mucosa grafts are the best urethral replacement for redo surgery and for stricture disease, and the meatus will be durable. In contrast, hypospadias repair with Snodgrass incised plate urethroplasty in primary cases, has gained widespread acceptance because it is versatile, and has the advantages of reliably creating a vertically oriented meatus, while having a lower complication rate than other techniques. These excellent results have been reported in literature as primary repair $(1,3)$. Although the use of Snodgrass urethroplasty has been extended from primary to re-operative hypospadias $(2,4,6,7)$, these reports do not appear to be very conclusive.

In the present series, we had 4 children in which the circumcision was performed by general physicians who overlooked their hypospadias. This was a new experience for us and despite the lack of prepuce, TIP technique had excellent results for these patients and without any complications (Table-1). Although the number of cases was, apparently limited, absence of the prepuce did not worsen the success rate of the procedure.

In another group of patients $(n=13)$, our complications rate $(30.7 \%)$ was related to four patients: i.e. two meatal stenoses, one stenosis with a small fistula and one dehiscence. Comparing these two small groups, it seems that the scar tissue on urethra is more important than lack of tissue for the flap and moreover influences the results. This study, and also the report of Yang et al. (8), demonstrated that the meatal stenosis is the most frequent form of complications in re-operative TIP urethroplasty especially in distal types. Although a wide neomeatus has been made, the meatal stenosis had the most complications. If we ignore circumcised patients (non re-operated hypospadias), results would be similar to Snodgrass and Lorenzo (3) who reported the usage of TIP urethroplasty to repair proximal hypospadias $(33 \%)$. Although their cases were proximal, complications in re-operation (2) were 3 in $15(20 \%)$, and is similar to those reported by Shanberg et al. (6), and Borer et al. (9) 24\%, 15\%, 
respectively. It is very important to note that in only one patient of our series, re-operation was necessary while others were cured by dilatation; this indicates that the ultimate success rate without another operation was $92.4 \%$. We had a patient with dehiscence glanuloplasty that underwent a successful second redo tubularized incised plate urethroplasty re-operation and responded satisfactorily.

Shanberg et al. (6) described the creation of a dartos flap from subcoronal shaft skin and reported only one fistula among their 13 patients. Çakan et al. (10) reported TIP urethroplasty, in 37 re-operative patients with a success rate of $78.4 \%$. The satisfactory outcomes were higher in patients $<5$ years. El-Sherbiny et al. (7) and others $(11,12)$ also reported the complication rate for hypospadias in adults being higher than children, however, in our series, they were not different. In Elicevik et al. series, the overall complication rate was $26 \%$ and the ultimate success rate of tubularized incised plate urethroplasty reoperation after treatment of complications was $97 \%$ (13).

For prevention of fistula, when possible, the neo-urethra was covered with a blanket of tunica vaginalis or some other buffering vascularized layer as an alternative flap for multilayer coverage of the urethroplasty. Therefore, the incidence of fistula was only one case that could be due to meatal stricture. Meatal stenosis is the most reported form of complication and usually responds to dilatation. Although uroflowmetry was not performed, meatal stenosis was evaluated clinically. Based on the opinion of Duckett et al., flowmetry is a good objective measure of caliber, but observation of a good full stream is subsequently more revealing in follow-up. Ideally one should have both (5).

The limitation of our study was the degree of scarring of the plate, because the most of our cases had a small scar on urethral plate and none of our patients had previously undergone a TIP urethroplasty repair. The authors conclude that this technique is adequate for patients with a heavily scarred urethral plate.

In conclusion, using the TIP urethroplasty as described by Snodgrass et al., is a suitable method for treating the re-operative cases. It can also be used successfully in patients who do not have a healthy skin flap and for circumcised patients when there is a complete lack of foreskin.

\section{CONFLICT OF INTEREST}

None declared.

\section{REFERENCES}

1. Snodgrass W: Tubularized, incised plate urethroplasty for distal hypospadias. J Urol. 1994; 151: 464-5.

2. Snodgrass WT, Lorenzo A: Tubularized incised-plate urethroplasty for hypospadias reoperation. BJU Int. 2002; 89: 98-100.

3. Snodgrass W, Koyle M, Manzoni G, Hurwitz R, Caldamone A, Ehrlich R: Tubularized incised plate hypospadias repair for proximal hypospadias. J Urol. 1998; 159: 2129-31.

4. Hayashi Y, Kojima Y, Mizuno K, Nakane A, Tozawa K, Sasaki S, et al.: Tubularized incised-plate urethroplasty for secondary hypospadias surgery. Int J Urol. 2001; 8: 444-8.

5. Duckett JW, Coplen D, Ewalt D, Baskin LS: Buccal mucosal urethral replacement. J Urol. 1995; 153: 16603.

6. Shanberg AM, Sanderson K, Duel B: Re-operative hypospadias repair using the Snodgrass incised plate urethroplasty. BJU Int. 2001; 87: 544-7.

7. El-Sherbiny MT, Hafez AT, Dawaba MS, Shorrab AA, Bazeed MA: Comprehensive analysis of tubularized incised-plate urethroplasty in primary and re-operative hypospadias. BJU Int. 2004; 93: 1057-61.

8. Yang SS, Chen SC, Hsieh CH, Chen YT: Reoperative Snodgrass procedure. J Urol. 2001; 166: 2342-5.

9. Borer JG, Bauer SB, Peters CA, Diamond DA, Atala A, Cilento BG Jr, et al.: Tubularized incised plate urethroplasty: expanded use in primary and repeat surgery for hypospadias. J Urol. 2001; 165: 581-5.

10. Cakan M, Yalçinkaya F, Demirel F, Aldemir M, Altug $\mathrm{U}$ : The midterm success rates of tubularized incised plate urethroplasty in reoperative patients with distal or midpenile hypospadias. Pediatr Surg Int. 2005; 21: 973-6.

11. Senkul T, Karademir K, Iseri C, Erden D, Baykal K, Adayener C: Hypospadias in adults. Urology. 2002; 60: 1059-62. 
12. Hensle TW, Tennenbaum SY, Reiley EA, Pollard J: Hypospadias repair in adults: adventures and misadventures. J Urol. 2001; 165: 77-9.
13. Eliçevik M, Tireli G, Demirali O, Unal M, Sander S: Tubularized incised plate urethroplasty for hypospadias reoperations in 100 patients. Int Urol Nephrol. 2007; 39: 823-7.
Accepted after revision:

July 14, 2008

\section{Correspondence address:}

Dr. Seyed Abdollah Mousavi

Department of Pediatric Surgery

Mazandaran University of Medical Sciences

Sari, Iran

Fax: + 98151 226-1996

E-mail: s_kavardi@yahoo.com.sg

\section{EDITORIAL COMMENT}

The authors report their experience with tabularized incised plate urethroplasty (TIPU) for hypospadias repair in 13 patients after previous failed attempts and in 4 after previous circumcision. Five patients experienced post-operative complications and 1 eventually required re-intervention. The authors conclude that the TIPU repair is a viable option even in such complex cases.

Although the conclusion is acceptable, patients with previous failed repairs and those with previous circumcision should be differentiated. In the latter, the issue is the lack of tissue for second-layer coverage of the urethroplasty, which may expose to an increased risk of fistula formation; in redo cases, instead, there might also be the issue of the presence of a scarred urethral plate unsuitable for the urethroplasty.

Indeed, in the absence of preputial tissue several alternatives exist for second-layer coverage of the urethroplasty accounting for the absence of increased morbidity in circumcised patients (1). For mid-shaft or distal hypospadias, as in the current series, the best choice is, in our opinion, the Y-to-I spongioplasty (2). This is performed rotating over the urethroplasty suture the residual spongiosum remnants, normally located underneath and laterally to the urethral plate. In order to achieve a double-layer coverage without overlapping sutures, a dartos flap based on the hypospadic meatus can be flipped over the re-approximated spongiosum. This is indeed the kind of coverage we also use in patients elected for preputial reconstruction.

Second-layer coverage can prove trickier, instead, in secondary repairs due to the paucity of good quality tissue available. Dartos flaps can often be mobilized laterally to the urethral plate and crossed above the neo-urethra in a "double breast" fashion. In a few cases, however, use of a tunica vaginalis flap can be the only option (3).

With regard to the degree of urethral plate scarring in redoes, if the plate appears healthy and supple, even despite previous hinging (4), a redo TIPU repair is worth attempting. This was indeed the case in all the patients in the present series where, however, it is of note that the vast majority of secondary repairs had a distal hypospadias, and had had only one 
previous surgery. The scenario might be quite different in cases with more severe forms of hypospadias and multiple previous failed repairs. Under these circumstances, the urethral plate can be severely and grossly scarred. If so, urethral plate substitution is, in our opinion, advisable and a two-stage oral mucosa urethroplasty is the procedure of choice (5).

\section{REFERENCES}

1. Snodgrass WT, Khavari R: Prior circumcision does not complicate repair of hypospadias with an intact prepuce. J Urol. 2006; 176: 296-8.
2. Yerkes EB, Adams MC, Miller DA, Pope JC 4th, Rink RC, Brock JW 3rd: Y-to-I wrap: use of the distal spongiosum for hypospadias repair. J Urol. 2000; 163: 1536-8; discussion 1538-9.

3. Gürdal M, Karaman MI, Kanberoğlu H, Kireççi S: Tunica vaginalis reinforcement flap in reoperative Snodgrass procedure. Pediatr Surg Int. 2003; 19: 64951.

4. Nguyen MT, Snodgrass WT: Tubularized incised plate hypospadias reoperation. J Urol. 2004; 171: 2404-6; discussion 2406.

5. Haxhirexha KN, Castagnetti M, Rigamonti W, Manzoni GA: Two-Stage repair in hypospadias. Indian $\mathrm{J}$ Urol 2008; 24: 226-232

Dr. Marco Castagnetti

Section of Pediatric Urology, Urology Unit Department of Oncological and Surgical Sciences University Hospital of Padova Padua, Italy

E-maIl:marcocastagnetti@hotmail.com

\section{EDITORIAL COMMENT}

The manuscript clearly reports the experience using tubularized incised plate (TIP) technique in 17 patients, 13 of them undergone previous hypospadias failure with different techniques (Mathieu in 2 , Thiersh-Duplay in 4 and, failed on-lay flap in one and unknown in 6), the remaining 4 patients were circumcised patients with intact urethral plate. In patients with intact urethral plate no complications were described. Instead, complications were observed in patients who underwent failed urethroplasty that causes scarring of the urethral plate. Reading this study, TIP urethroplasty continues to be the first surgical choice in hypospadia repair.

Otherwise, in those cases with urethral plate too scarred and where urethral vascularization has been compromised by previous surgery, we believe that it would be interesting to use a modification of the tubularized incised plate technique by adding a dorsal free buccal or lingual mucosal graft in the attempt to avoid meatal stenosis.
Under these conditions, most authors have proposed a one stage procedure using the graft as a ventral onlay or tube, with a complication rate of $32 \%$ and $50 \%$, respectively (1), Snodgrass and Elmore (2) reported on dorsal buccal mucosa grafts in a two stage operation with the overall success rate of $65 \%$.

In 2008 Ye et al. expanded Hayes and Malone's one step technique even to complex re-do hypospadias with long urethral strictures with interesting results (3). The oral graft is placed dorsally on a good quality vascular bed of tunica albuginea, with tubularization of the composite urethra. The dorsal inlay buccal mucosal graft has the advantage of the TIP technique: a) enlarge diameter of the neo urethra; b) decrease recurrence of meatal stricture. Our unpublished experience with lingual mucosal graft in single stage dorsal inlay urethroplasty in previous failed hypospadias repair is very similar with that of Ye et al. 
In conclusion we think that single stage dorsal inlay oral mucosa approach is a helpful option for complex re-do hypospadias when there is no virgin urethral plate.

\section{REFERENCES}

1. Hensle TW, Kearney MC, Bingham JB: Buccal mucosa grafts for hypospadias surgery: long-term results. J Urol. 2002; 168: 1734-6; discussion 1736-7.
2. Snodgrass W, Elmore J: Initial experience with staged buccal graft (Bracka) hypospadias reoperations. J Urol. 2004; 172: 1720-4; discussion 1724.

3. Ye WJ, Ping P, Liu YD, Li Z, Huang YR: Single stage dorsal inlay buccal mucosal graft with tubularized incised urethral plate technique for hypospadias reoperations. Asian J Androl. 2008; 10: 682-6.

\author{
Dr. Alchiede Simonato \& \\ Dr. Matteo Orlandini \\ Clinica Urologica "L.Giuliani" \\ University of Genoa \\ Genoa, Italy \\ E-mail: alchiede.simonato@unige.it
}

\section{EDITORIAL COMMENT}

In this article, authors retrospectively reviewed the outcome of tubularized incised plate urethroplasty (TIPU) for hypospadias reoperations and repairs in circumcised patients. In their experience, 4 of 17 cases had complications. While reoperation was required in 1 case, the other 3 cases whose complications were meatal stenosis in 2 and stenosis with small fistula in 1 were cured by dilation. The authors concluded that TIPU is a safe and efficacious procedure for hypospadias reoperations and repairs in circumcised patients.

Currently, TIPU is widely accepted for primary repair of distal hypospasias and hypospadias reoperations. One of the key points in this procedure in reoperative cases would be quality of urethral plate. Several studies reported in the literature have suggested that complication rate increases in reoperative cases if the urethral plate has been resected or is obviously scarred $(1,2)$. Therefore, careful estimation of urethral plate is crucial if TIPU is planned for hypospadias reoperation.

The other key point is reinforcing layer of neourethra. Spongioplasty and neourethral coverage with dorsal dartos flap are commonly used in primary repair by TIPU to reinforce neourethra $(3,4)$. However, urethral sponge tissue beside the urethral plate is usually unavailable in reoperative cases. Hence, neourethral coverage by dorsal dartos flap would have more important role to prevent complications. In circumcised cases as reported in this article, dorsal dartos flap may be inadequate to reinforce the neourethra though urethral sponge tissue neighboring the urethral plate is preserved for spongioplasty. In such cases, authors made efforts to cover the neourethra with pedicled subcutaneous tissue. Tunica vaginalis is also reported as an alternative tissue for neourethral coverage if subcutaneous tissue may be inadequate to reinforce the neourethra (5). These procedures for coverage are quite important and should be performed to prevent operative complications.

I agree with authors that TIPU is safe and effective for hypospadias reoperations. However, preoperative estimation of urethral plate as well as access to information of previous surgery should be done to decide the surgical procedure in reoperative cases. Also, during surgery, neourethral coverage with well vascularized tissue should be performed to avoid complications. 


\section{REFERENCES}

1. Snodgrass WT, Lorenzo A: Tubularized incised-plate urethroplasty for hypospadias reoperation. BJU Int. 2002; 89: 98-100.

2. Eliçevik M, Tireli G, Demirali O, Unal M, Sander S: Tubularized incised plate urethroplasty for hypospadias reoperations in 100 patients. Int Urol Nephrol. 2007; 39: 823-7.

3. Yerkes EB, Adams MC, Miller DA, Pope JC 4th, Rink RC, Brock JW 3rd: Y-to-I wrap: use of the distal spongiosum for hypospadias repair. J Urol. 2000; 163 : 1536-8; discussion 1538-9.

4. Djordjevic ML, Perovic SV, Vukadinovic VM: Dorsal dartos flap for preventing fistula in the Snodgrass hypospadias repair. BJU Int. 2005; 95: 1303-9.

5. Gürdal M, Karaman MI, Kanberoðlu H, Kireççi S: Tunica vaginalis reinforcement flap in reoperative Snodgrass procedure. Pediatr Surg Int. 2003; 19: 64951.

Dr. Kimihiko Moriya
Department of Urology
Hokkaido University Graduate School of Medicine
Sapporo, Japan
E-mail: k-moriya@med.hokudai.ac.jp

The discussion compares the study with numerous other studies achieving similar results. However, other operative techniques for redo hypospadias like buccal mucosa flaps are not mentioned.

Due to the very inhomogeneous group and the small number of cases no conclusion can be drawn. This study does show some aspects of the TIP procedure, however it does not prove at all that the TIP procedure is suitable for redo hypospadias in patients with or without foreskin.

Dr. Maike Beuke Urologisches Zentrum Hamburg Asklepios-Klinik Harburg Hamburg, Germany E-mail:mbbeuke@web.de 